\title{
Feminismo y escritura: los ensayos de Diamela Eltit
}

\section{Feminism and Writing: the Essays of Diamela Eltit}

\begin{abstract}
Resumen
En este artículo me propongo indagar en los ensayos de Diamela Eltit haciendo especial hincapié en dos tópicos: el feminismo y la escritura. Para ello, analizo un corpus de textos publicados en los libros Emergencias (2000), Signos vitales (2008) y Réplicas (2016) a partir de tres operaciones ideológico- discursivas: la deconstrucción del cuerpo, la reconstruccion de genealogías literarias femeninas y la reflexión sobre la escritura. Sostengo, a modo de hipótesis, que la práctica ensayística de la autora constituye un ejercicio crítico a través del cual se convoca a una multiplicidad de voces para desnaturalizar y repensar los recorridos del cuerpo, la subjetividad y el lenguaje en el marco de las sociedades contemporáneas. El marco teórico- metodológico propende a articular conocimientos de los estudios culturales y de la crítica feminista. En este sentido, el trabajo pretende no solo explorar una faceta escasamente abordada dentro de los estudios en torno a Eltit sino también caracterizar las variaciones y tensiones referidas al feminismo y a la escritura que gravitan dentro de su producción literaria.
\end{abstract}

Palabras claves

Diamela Eltit, crítica feminista, escritura, cuerpo, genealogías literarias de mujeres

\begin{abstract}
I propose in this article to look into the essays of Diamela Eltit and focus on two topics: feminism and writing. For this purpose, I will analyze a text corpus published in the books Emergencias (2000), Signos vitales (2008) and Réplicas (2016) from three ideological and discursive operations: the deconstruction of the body, the recognition of the female literary genealogy and the reflection about writing. My hypothesis is that the author's essay practice constitutes a critical exercise through which a multiplicity of voices is summoned in order to denature and reconsider the paths of the body, the subjectivity and the language within the frame of the contemporary societies. The theoretical and methodological frame tends to articulate the knowledge of cultural studies and of feminist critique. For this reason, this paper
\end{abstract}


is not only expecte to explore a poorly tackled facet within the studies about Eltit, but also to characterize the variations and tensions related to feminism and writing that gravitate in her literary work.

Keywords

Diamela Eltit, feminist critique, writing, body, female literary genealogies.

\section{Introducción}

Como práctica de autoerotismo, la escritura capitanea una búsqueda en los bordes, en los intersticios donde las prácticas y saberes se confunden, para encontrar ahí, donde todavía todo está por inventar, la fuerza para desencantarnos de este paisaje de mundo y desacomodar lo que está solidificado, silenciado e invisibilizado. (flores 221)

El ensayo es un género cuya culpabilidad no puede ofrecer garantías, sino apenas el módico coraje de arriesgarse al indefectible error. (Grünner 22)

La crítica feminista se ha encargado de señalar la alianza entre capitalismo y patriarcado como formas históricas de subyugación y opresión sobre el cuerpo de las mujeres. En efecto, en las sociedades capitalistas se ha desarrollado una división sexual de las tareas que somete la mano de obra femenina a la función reproductora de la fuerza de trabajo y, a la vez, se ha constituido un nuevo orden patriarcal basado en la exclusión de las mujeres del espacio público y su subordinación a los hombres (Federici). Este sistema de relaciones desiguales funciona a partir de una compleja articulación de mecanismos que justifican y mistifican las contradicciones imperantes dentro de las relaciones sociales a la vez que denigran la naturaleza racial y de género de aquellos a quienes explota (Federici). Además de las condiciones económicas y políticas, una de las dimensiones centrales a través de las que se ejecuta la reproducción de este sistema es de orden social y cultural. Como sostiene Giulia Colaizzi, las sociedades patriarcales no solo implican un régimen de propiedad privada, sino también de propiedad lingüística y cultural por cuanto el signo masculino se instituye como el logos que regula la producción de 
sentidos y determina la naturaleza de las relaciones entre los sujetos (113). La crítica feminista deviene, así, en modelo de crítica cultural que, a través de un uso político del análisis del discurso, busca desmontar los significados que se inscriben sobre el cuerpo y, especialmente, sobre la "mujer" (Richard, "La crítica feminista" $76)^{1}$.

En el escenario chileno posterior al Golpe de Estado de 1973 las problemáticas del género y del feminismo han transitado un camino sinuoso atravesado profundamente por las condiciones socio-históricas. De acuerdo con Nelly Richard, durante la Dictadura, el feminismo adquirió una notable fuerza de cuestionamiento teórico-político en el que se articulaban reivindicaciones ciudadanas y una movilización antidictatorial. La conciencia de género en los 80 procuró comprometer a las mujeres en un proyecto de acción solidario para con las demás fuerzas de recuperación democrática y, al mismo tiempo, “[...] descentrar y complejizar la referencialidad al poder de estado que, en su versión centralizante y totalizante, orienta un entendimiento de la política tradicional que deja fuera de su esfera las micropolíticas de lo subjetivo y lo cotidiano" (Richard, Feminismo 58). En los gobiernos de la Transición se observa, en general, repliegue de los movimientos de mujeres motivado, entre otras cosas, por la hegemonía de una lógica conciliatoria que margina del discurso público a las voces más combativas y por el desplazamiento de la figura de la activista-militante hacia ámbitos de profesionalización con gran protagonismo de las organizaciones no gubernamentales $^{2}$. En los últimos años, el feminismo ha retomado protagonismo a

${ }^{1}$ Sobre las relaciones entre Análisis del Discurso y feminismo, Giulia Colaizzi sostiene lo siguiente: "En este sentido, mi tesis es que feminismo es teoría del discurso, y que hacer feminismo es hacer teoría del discurso, porque es una toma de conciencia del carácter discursivo, es decir, históricopolítico, de lo que llamamos realidad, de su carácter de construcción y producto $\mathrm{y}$, al mismo tiempo, un intento consciente de participar en el juego político y en el debate epistemológico para determinar una transformación en las estructuras sociales y culturales de la sociedad, hacia la utopía -una utopía indispensable- de un mundo donde exclusión, explotación y opresión no sean el paradigma normativo" (Colaizzi 117).

2 "En sintonía con las demás reconversiones que agenció el dispositivo de la transición chilena, la crítica feminista dejó la fragmentariedad dispersa por el reagrupamiento operativo; la pulsión nómade de ruptura por la acumulación y capitalización discursiva del valor- "saber"; el desorden imaginativo por la racionalización profesional; los desgastes de la utopía militante por una lógica 
nivel global en un contexto marcado por el despliegue del capitalismo salvaje que intensifica la precariedad del trabajo y de la vida de amplias capas de la población y por el crecimiento vertiginoso y la visibilización de la violencia de género. Las recientes movilizaciones estudiantiles feministas en Chile, por ejemplo, han logrado instalar en el debate público temas como el abuso sexual y de poder en los contextos educativos y la necesidad de repensar la educación desde una perspectiva no sexista (Miranda y otras 33).

En este marco, la actividad artística y literaria de Diamela Eltit en los últimos 40 años ha establecido distintitos diálogos y ha intervenido a través de diversas operaciones críticas en el debate acerca del autoritarismo de la alianza mercado- estado, la memoria y las problemáticas de género. Tanto en sus trabajos como performer -en los que moviliza marcas sexuales y políticas impresas en el cuerpo como estratagema de denuncia que exhibe la violencia militar (Richard Feminismo, 90)- como en las novelas Lumpérica (2008) o Impuesto a la carne (2010) - en las que la materialidad de lo femenino se presenta como territorio en el que se yuxtaponen y subvierten discursos e imágenes asociados con el (bio) poder (Barrientos)- se convoca a una multiplicidad de voces para deconstruir y repensar los recorridos del cuerpo, la subjetividad y el lenguaje en la sociedad contemporánea.

En este trabajo me propongo indagar en una faceta escasamente abordada por la crítica literaria en torno a la producción eltiana: su rol como ensayista. En efecto, la autora ha publicado hasta el momento tres volúmenes en los que se recopilan textos catalogados genéricamente como escritos ensayísticos: Emergencias. Escritos sobre literatura, arte y política (2000), Signos vitales. Escritos sobre literatura, arte y política (2008) y Réplicas. Escritos sobre literatura, arte y política (2016). En cada uno de estos libros, Eltit se construye como lectora de los discursos de circulación social esbozando herramientas diversas que van desde la crónica urbana hasta la crítica de arte a través de registros 
que alternan entre la formalidad de las revistas científicas y las complicidades pactadas en textos de circulación masiva o en entrevistas (Cabrera 443). Más que por la preeminencia de alguna trama textual argumentativa o de algún signo de identidad discursiva, estos escritos se revelan como ensayísticos en la manera en que ponen en escena un ejercicio intelectual que se desprende de las garantías para desandar, dislocar y desarmar los signos de lo que se pretende conocido (Richard, La Generalización). Asimismo, al analizar los sintagmas que dan título a los libros es posible señalar una ambivalencia semántica que insiste en el carácter polémico y profundamente comprometido con la vida social y política de sus intervenciones intelectuales.

Atendiendo a lo señalado, en este artículo focalizo mi atención en los valores y significaciones con las que se asocian la práctica de la escritura y la crítica feminista en los ensayos de la autora. Para ello, organizo un corpus de textos en torno a tres grandes operaciones ideológico- discursivas: la deconstrucción del cuerpo, el reconocimiento de genealogías literarias femeninas y la reflexión acerca de la escritura. Dentro de la primera operación se incluye una serie de textos que asumen el desafío de desmontar los discursos que asedian y diseñan los cuerpos (especialmente femeninos): "Sociedad anónima" (2000), "Clases de cuerpo y cuerpos de clase" (2008), "Cargas y descargas" (2008), "Se deben a sus circunstancias. Baños colectivos de mujeres asiladas en el Hospital Psiquiátrico Philippe Pinel" (2008), "La plenitud de la apariencia" (2008), "Con este cuerpo, con este talle, no tengo envidia ni ruego a nadie" (2016) y "La mujer o el cuerpo del delito" (2016). En segundo lugar, al hablar de la reconstrucción de genealogías literarias femeninas analizo un conjunto de textos en los que Eltit propone una relectura de escritoras como Marta Brunet y Gabriela Mistral para revisar las políticas de la literatura y de lo femenino hegemónicas en el campo literario chileno3: "Sociedad anónima" (2000), "Personaje en correspondencia" (2000), "El

${ }^{3}$ A propósito del tema, resulta interesante revisar la reseña que Nelly Richard ("La Generalización") elabora sobre Réplicas. Escritos sobre literatura, arte y política de Eltit (2016). La autora destaca 
tejido ilegal" (2008), "Contante y sonante" (2008), "Escuchar el dolor, oír el goce" (2016), "Presentaciones, representaciones y re- presentaciones" (2016), "Yo soy, envejeciendo, una asiática" (2016), "Dios veló sobre mí, no mis compatriotas" (2016) y "Marta Brunet en la fértil provincia" (2016). En tercer lugar, me remito a escritos en los que la escritora despliega un doble movimiento en el que reflexiona acerca del carácter social y político de la escritura como tecnología asociada con prácticas de poder a la vez que se propone pensar su propia trayectoria estética. Aquí se incluyen: "Errante, errática" (2000), "Acerca del hacer literario" (2000), "Tensiones e intenciones" (2008), "Con la cultura en la mano" (2016) y "En la zona intensa del otro yo misma" (2016). Hacia el final del artículo esbozo algunas conclusiones tendientes a caracterizar estas operaciones como dispositivos de interpelación y subversión epistemológica respecto de formaciones ideológicas de carácter patriarcal, racial, militar y neoliberal hegemónicas.

\section{La deconstrucción del cuerpo}

El cuerpo y sus modulaciones estético-políticas es uno de los nudos temáticos que atraviesa la producción ensayística de Eltit (Morales 13). Este cuerpo se manifiesta como espacio estratégico de configuración y confrontación conceptual. Se halla habitado de síntomas que delatan al poder, exhibe los dispositivos y las series históricas que lo producen y lo transforman (Giorgi). Los ensayos elaboran un inventario de cuerpos que funciona a la manera de una carta de navegación para comprender -y desnaturalizar- cómo se entrecruzan y yuxtaponen no solo las nociones de género, raza y clase sino también condiciones históricas y geopolíticas en las dinámicas sociales contemporáneas. Para ello, la autora hace uso de una amplia caja de herramientas en las que resuenan las lecturas de pensadores de distintos lugares disciplinares y geográficos tales como Michel

que los ensayos de Eltit desnaturalizan y exhiben la arrogancia de la generalización masculina de la figura del intelectual público. 
Foucault, Jacques Rancière, Giorgio Agamben, Antonio Negri, Judith Butler, Nelly Richard, Conztanzx Álvarez Castillo y Jean Franco, entre otros.

En este recorrido crítico, una de las operaciones ideológico-discursivas de mayor envergadura consiste en la deconstrucción del cuerpo- signo. Esto quiere decir, desde una perspectiva derrideana, que la pregunta por el cuerpo en los ensayos se presenta como una forma de interpretación y experimentación para comprender y desmontar el funcionamiento de ciertos discursos o núcleos de sentido asociados a él. En consecuencia, se procura desautorizar y desandar, teórica y prácticamente, los axiomas hermenéuticos que pretenden ser totalizantes.

Siguiendo con el orden de los argumentos, resulta indispensable preguntarse cuáles son las definiciones de cuerpo que se construyen en los ensayos del corpus. Una primera formulación de carácter general se presenta en el texto "Cuerpos de clase y clases de cuerpo" (2008). Allí la autora se propone pensar cómo se construyen discursivamente los cuerpos infantiles y las figuras maternas en la sociedad chilena a partir de tres novelas: Alsino (1920) de Pedro Prado, Patas de perro (1965) y El obsceno pájaro de la noche (1970) de José Donoso. Con una marcada influencia de la crítica biopolítica de Michel Foucault y Giorgio Agamben, Eltit define al cuerpo como un diseño social que porta sobre sí el inacabable malestar de la cultura ("Clase de cuerpos" 30). Asimismo, la autora destaca el funcionamiento discursivo de estos diseños corporales como argumento acerca del carácter social de las prácticas artísticas y literarias. Afirma que la dimensión política de dichas prácticas se manifiesta a través de la intervención ${ }^{4}$ y subversión de sentidos:

El cuerpo como diseño social, como mapa de discursos que establecen construcciones de sentido, continúa imperturbable su tránsito en tanto agudo campo de prueba de los sistemas sociales [...] no cesa en su condición jerarquizada, siempre experimental. De la misma manera que la

${ }^{4}$ Junto con Nelly Richard (Cuestionario) defino a la idea de intervención como un corte transformador sobre una superficie de conocimientos normalizados y/o cristalizados. 
historia recoge el cuerpo de los acontecimientos, la literatura acopia en sus ficciones las intensidades que portan los relatos corporales y los dispone en una exacta correlación con los sistemas productivos y sus técnicas. Así, desde una perspectiva analítica, se podría aludir a una suerte de cuerpos técnicos o cuerpos funciones, en tanto actúan como los soportes pensantes y parlantes en que se van a anclar las experiencias económico- políticas. ("Clase de cuerpos"15)

Por otra parte, en el ensayo "Se deben a sus circunstancias. Baños colectivos de mujeres asiladas en el Hospital Psiquiátrico Philippe Pinel" ("Se deben a sus circunstancias"), la mirada de la ensayista se focaliza sobre las fotografías de Paz Errázuriz ${ }^{5}$ para explorar el universo de los cuerpos institucionalizados por una de las tecnologías modernas de subjetivación: el hospital. La imagen de los cuerpos en las duchas remite a un doble repertorio: por un lado, a los cuerpos torturados y arrasados por la violencia de la Dictadura y, por otro, a los cuerpos marginales en el escenario de un esteticismo neoliberal ${ }^{6}$. El cuerpo abyecto, en este sentido, se revela como dispositivo que interrumpe y desordena los trazos socio- políticos de las corporalidades: "Estos desnudos, en estado arcaico, dan cuenta de una falla social, una fractura que se disuelve en una multiplicidad de signos que desnudan el desnudo como una laboriosa construcción” (“Se deben” 221).

Precisamente, una de las preguntas que gravita a lo largo de los ensayos de Eltit consiste en las causas de la centralidad del cuerpo femenino dentro de los debates y disputas socio- culturales. En el texto "Con este cuerpo, con este talle, no tengo envidia ni ruego a nadie", con la intención de elaborar una reseña crítica del

${ }^{5}$ A comienzos de la década del 90, la fotógrafa chilena Paz Errázuriz emprende el proyecto de retratar a la población del Hospital Psiquiátrico Philippe Pinel, ubicado en la localidad de Putaendo, Viña del Mar. Como parte de este proyecto, Errázuriz y Eltit trabajan conjuntamente en el libro El infarto del alma (1994) en el que conjugan imagen y texto.

6 "En los escenarios sociales hegemónicos, el desnudo carece de cuerpo. Se trata, en realidad, de un modelo de cuerpo, una copia, un símil, el resultado de un imaginario social que se deja caer sobre el cuerpo femenino para ensayar allí un deseo de desnudo, un modelo de domesticación corporal, precisamente, desde la inoculación de un modelo de cuerpo, de desnudez, de eróticas, de estéticas de lo femenino" (Eltit, "Se deben" 221). 
libro La cerda punk: ensayos desde un feminismo gordo, lésbiko, antikapitalista y antiespecista (2014) de Constanzx Álvarez Castillo, apunta un conjunto de afirmaciones respecto de la relación entre cuerpo femenino, capitalismo y patriarcado. El cuerpo humano se presenta como una plataforma de negocios en la que comparecen discursos contradictorios que "[...] apuntan directamente a establecer universos corporales sicotizados para así profundizar la despertenencia fundada en un abismante vacío" (Eltit, "Con este cuerpo" 29). Desde esta perspectiva, las ficciones del cuerpo ${ }^{7}$ constituyen una máquina de guerra en la que la corporalidad femenina (especial pero no exclusivamente) se halla ultra asediada como objetivo estratégico de dominación y colonización. Un ejemplo claro de esto se observa en el texto "La mujer o el cuerpo del delito" al discutir respecto de la legalización del aborto:

La pregunta es por qué en Chile no pueden enfrentar un gran diálogo sobre este tema estratégico. Y las respuestas pueden ser porque el cuerpo de la mujer está asediado y cautivo por la hegemonía y cualquier debate emancipador de su condición provoca un pavor inconmensurable en la totalidad de los estamentos, y muy especialmente en esta derecha- dinero que tenemos. (49)

Por otra parte, en "Cargas y descargas" reflexiona a propósito de la figura literaria de Juana Lucero, protagonista de una novela homónima publicada en 1902 por Augusto D' Halmar. A partir de este personaje el ensayo organiza una colección en la que convergen piezas literarias, audiovisuales y episodios de la cultura: la novela Hasta ya no ir (1996) de Beatriz García Huidobro, el film B-happy (2003) de Gonzalo Justiniano y la experiencia histórica de los asesinatos y desapariciones

\footnotetext{
${ }^{7}$ En este texto la autora utiliza el término ficción para referirse a la construcción discursiva de los cuerpos en la sociedad. Cito: "[...] El cuerpo es nada más ni nada menos que la producción (ficcional) de un conjunto de discursos sociales que lo remodelan a partir de una captura que es totalmente posible pues: "el cuerpo no es"” (Eltit, "Con este cuerpo" 28).
} 
de mujeres (en su mayoría prostitutas) acontecidas en la comunidad de Alto Hospicio a fines de la década del 90. Juana Lucero se erige como un paradigma de la conjunción trágica de pobreza, cuerpo femenino y prostitución en una sociedad patriarcal. En sentido resuenan las palabras de Rita Segato respecto de los crímenes contra las mujeres en Ciudad Juárez: la violación o el asesinato de mujeres no son hechos aislados ni delitos privados sino actos a través de los cuales se ejerce un poder sobre un colectivo para imponer un orden. La emancipación sexual de las mujeres, en este contexto, se perfila como un terror comunitario: "Ya se ha disuelto el pánico a la apropiación de los medios de producción presagiado por Marx; en cambio, circula el terror ante cuerpos que, en las fantasías más persecutorias, van directo a desvalijar, a atacar acumulaciones puntuales y hasta fugaces" (Eltit, Cargas 31).

Como se desprende de lo señalado anteriormente, el cuestionamiento de las jerarquías de género implica repensar las lógicas de producción y reproducción de las condiciones materiales de existencia. Es por ello que se hace necesario insistir en la pregunta por el lugar de las mujeres en las disputas sociales, incluso en los espacios de activismo. En esta dirección, Eltit plantea una profunda crítica a la invisiblización de las mujeres y lesbianas en organizaciones de diversidad como Movilh $^{8}$ y Fundación Iguales ${ }^{9}$ que responden no solo a una hegemonía masculina bajo las máscaras de la diversidad, sino que sus lógicas de intervención pública se pliegan ante el consenso del orden heteropatriarcal. En palabras de la autora, estamos ante organizaciones de signo "heterogay" (Eltit, "El cuerpo del delito" 48).

Ahora bien, se hace necesario preguntarse qué hacer con las problemáticas de género, cómo desprenderse de una tradición de olvido y silencio para nombrar las experiencias de los cuerpos que han sido relegados de la dicotomía masculinofemenino, cómo descentrar e interrumpir las políticas de feminización de los

\footnotetext{
${ }^{8}$ Movimiento de Integración y Liberación Homosexual (Movilh) es una agrupación chilena fundada en 1991 que defiende los derechos de personas lesbianas, gays, bisexuales y trans e intersex (LGBTI).

${ }^{9}$ La Fundación Iguales es una ONG chilena nacida en 2011 con el objetivo de trabajar en pos de la igualdad de derechos y de la no discriminación de la diversidad sexual.
} 
cuerpos subalternos desde la especificidad de las geopolíticas latinoamericanas. Al respecto, en "Sociedad anónima" la autora se pregunta cuál es el escenario social que nos ha dejado el siglo XX (y el interrogante podría ampliarse a las primeras décadas del XXI) y ensaya una respuesta desencantada a la manera de un texto teatral marcado por detalles crueles: la memoria de Allende, el terremoto ideológico que significó Pinochet, el advenimiento del empresario como figura que desplaza a la opinión pública, la comercialización de las ideologías y una mercantilización de las representaciones de género que se retrotrae a esquemas decimonónicos. Sin embargo, resalta el carácter refractario de ciertos cuerpos (disidentes respecto de los mandatos de la tradición, recorridos por la locura o arrasados por la pobreza) que se resisten a la seducción del consumo y de los modelos hegemónicos (Eltit, "Sociedad" 34). Desde ese intersticio, postula algunos de los desafíos que debe asumir la crítica de género:

[...] Enfatizar que la cuestión de género es una construcción social susceptible de ser modificada a través de los lenguajes y vulnerar así las costumbre de identificar linealmente la relación femenino- mujer y hombre- masculino (homologar biología y cultura). El desafío más interesante es politizar los géneros para descomprimir así las redes de opresión que rodean al sujeto condenado a ser modelado por los intereses volubles del presente.

Se trata de entender que estamos bajo los efectos de una arrasante maquinaria de producción de subjetividades en las cuales se cursan sensaciones, emociones, discursos, certezas, estilos. Se trata de entender que esta es una maquinaria burguesa: excluyente, clasista y racista. (40)

Como se observa en los ensayos, el cuerpo se manifiesta como el espacio crítico sobre el que la autora se desplaza epistemológica y políticamente para leer, a contra pelo, los restos y sedimentos de discursos sociales. La mirada de la crítica se posiciona en los cuerpos que desencajan, re- cifran sus lugares y presionan sobre 
las normas y etiquetas (Eltit, "La plenitud" 148) y, a la vez, asume una conceptualización de género como pliegue estratégico (Richard, Feminismo) en tanto permite agrupar una serie de gestos disruptivos respecto del ordenamiento heteropatriarcal pero que, además, es rebasado por la proliferación de: “[ ...] sensibilidades que atraviesan y horadan los mandatos para sumergirse de lleno en la exploración de códigos que reformulan las categorías binarias de femenino o masculino" (Eltit, "La Plenitud” 148).

\section{La reconstrucción de genealogías literarias femeninas}

Reconstruir genealogías implica desnudar un conjunto de problemas vinculados con la formulación de los relatos que pretenden ser explicativos de la realidad a la vez que exige asumir el carácter situado de tal actividad. En el caso particular de las genealogías de mujeres se asume el desafío de recuperar "[...] la historia de nuestras antepasadas, de reconocimiento de los lazos que nos ligan con ellas, a sabiendas de que tal recuperación se produce a partir de un interés político y cognoscitivo ligado a la necesidad de historizar nuestra presencia en las luchas del pasado" (Ciriza 614). En este sentido, es posible revisar cómo se reconstruyen las tradiciones teóricas y políticas de los sectores subalternos y, en el caso especial de las mujeres, cuál es el peso que estas reconstrucciones tienen sobre los procesos de legitimación de demandas y de significación de su lugar y sus derechos en el espacio público.

En los ensayos de Eltit se observa una problematización permanente acerca del lugar de las mujeres dentro de los escenarios políticos e intelectuales: se indaga en las omisiones de la historia y se examina detenidamente las modalidades a través de la que se construyen las agencias femeninas. Así, es posible advertir en el corpus de ensayos el despliegue de una mirada genealógica que le permite elaborar un diagnóstico respecto de las condiciones sociales de enunciación de la palabra femenina a la vez que invoca las palabras de sus antecesoras para inscribir su propia 
gesta escritural dentro de una lucha (Grasselli y Yañez). Así las cosas, en el caso del campo literario chileno, la autora señala un malestar por cuanto el signo que predomina, autoriza y legitima las producciones se caracteriza por una misoginia cultural:

En Chile no deja de ser interesante examinar la relación género y literatura en los años de transición democrática y cómo, en la actualidad, se puede ver la sincronía y complicidad (en último término política) de un conjunto de autores empeñados en mantener lo literario en el ámbito de lo masculino, un grupo de autores que lideran un escenario que resulta más social que literario y donde sus discursos son simétricos y funcionales con una cierta burguesía a la que aspiran representar [...]. (Eltit, "Sociedad" 39)

Por otra parte, otra de las aristas de este malestar se manifiesta en relación con el mercado editorial y el auge de etiquetas comerciales que califican a ciertas prácticas literarias como "femeninas" o "de mujeres". Desde la perspectiva de la autora, este fenómeno es, por lo menos, paradójico ya que, si bien coopera en la reparación de omisiones femeninas dentro de las historias de la literatura, profundiza una especie de separación de las mujeres a través de una biologización de la escritura: "La literatura como campo exploratorio con los signos le pertenece a los hombres. En los extramuros está aglomerada la escritura de mujeres como subproducto, como decoración” (“Contante” 274-275). Además, la autora señala que las producciones que se agrupan bajo dichas etiquetas se desprenden de cualquier intención de renovación estética y se pliegan al reordenamiento y readecuación de lo femenino dentro de los modelos del relato tradicional ("Sociedad" 39).

Así las cosas, la propuesta crítica de Eltit se sitúa en un doble campo de batalla: entre las omisiones y sumisiones que se ejecutan dentro del campo literario y la cristalización de las etiquetas de género como fórmulas de mercadotecnia. En 
ese doble régimen de acción, la autora se acerca a los símbolos convocados por dos grandes figuras/ madres de la escritura femenina chilena: Gabriel Mistral (18891957) y Marta Brunet (1897- 1967). En ambos casos, la estrategia de la autora consiste en interrogar las construcciones de género asociadas a las escritoras y el modo en que ellas las interpelan.

En primer lugar, al leer las cartas de Mistral con Isauro Santelices ${ }^{10}$ (Eltit, "Personaje en correspondencia"), esboza un recorrido crítico- biográfico que hace foco en las dificultades políticas, económicas y culturales que debe enfrentar la poeta en su construcción pública como escritora y defensora de causas sociales tales como el indigenismo. Por otra parte, dentro del corpus se distingue un conjunto de textos que analizan la correspondencia amorosa entre Mistral y Doris Dana ${ }^{11}$. En estos textos, Eltit indaga en las escenas de goce y de dolor en las que el cuerpo ocupa la escena principal a pesar de que en la construcción de la imagen pública de la poeta opera un silenciamiento de todos aquellos episodios que la alejan del encuadre moral de "maestra de la patria". Se propone leer, así, a la figura de Mistral como una zona geográfica, como un intersticio y como una sede de secretos (Eltit, "Presentaciones") a través de la figura del doblez:

Su trabajo poético respondió parcialmente a las demandas epocales que exigieron que su letra tuviera como protagonistas a la maestra y a la madre. Pero, en otro vórtice de su obra, más subversivo y mucho más complejo, escribió a la "otra", ese sujeto femenino que se desmarcó de las convenciones dominantes para dar cuenta de otras subjetividades fundidas en la poderosa fuerza del deseo. (Eltit, "Dios veló" 89)

${ }^{10}$ Isauro Santelices, escritor y pedagogo chileno encargado editor del libro Mi encuentro con Gabriela (1972) en el que recopila la correspondencia que intercambia con la autora.

${ }^{11}$ Doris Dana (1920- 2006) escritora norteamericana, pareja y secretaria de Gabriela Mistral entre 1946 y 1957. En estos textos, Eltit hace referencia a la publicación en el año 2009 del libro Niña errante: cartas a Doris Dana, selección de 250 cartas en las que se hace explícito el vínculo amoroso entre ambas escritoras. 
Este doblez se sintetiza en la pregunta: “QQué haremos con el lesbianismo de Gabriela Mistral?, ¿Cómo podremos ingresar su deseo y el tránsito de su deseo en los espacios públicos sin escándalos y sin ofensas?” (Eltit, "Yo soy envejeciendo" 86). El presente de la interrogación se manifiesta como una estrategia que desnuda el carácter misógino y heterosexual que reglamenta las políticas de la literatura. Eltit desarrolla, en este sentido, un homenaje póstumo para Mistral a través de una desmonumentalización de su figura.

En el caso de Marta Brunet, la autora destaca de qué manera sus prácticas literarias se desplazan respecto de modelos culturales cosmopolitas con la intención de internarse en una poética de la soledad y del desamparo que desmenuza problemas de las sociedades rurales de Chile (Eltit, "El Tejido"). Además, la lectura de Eltit rescata las novelas de Brunet como un episodio particular dentro de las letras chilenas por cuanto, en la primera mitad del siglo XX, se propone exhibir la arbitrariedad de las convenciones sociales y textualizar el signo "mujer" desde una perspectiva crítica: "Marta Brunet no se propuso la redención del sujeto mujer, sino más bien señaló críticamente cómo la sociedad "producía" lo femenino, sometido a espejismos y fantasmas emotivos cursis, que ensombrecían su vida más material y concreta" (Eltit, "Marta Brunet” 102).

Tanto en el caso de Mistral como en el de Brunet, se puede decir que uno de los tópicos que resalta Eltit es el de una batalla por los signos a través de los que se recubre la idea de lo femenino. En esta breve genealogía se destaca la importancia del trabajo con la literatura entendida como una caja de resonancia donde se intersectan las pulsiones vitales con preocupaciones estéticas y políticas que buscan horadar las leyes de los lenguajes hegemónicos. En el dolor y en el goce, las letras de estas autoras registran una experiencia histórica y disputan un campo de representaciones más amplio. 


\section{La reflexión sobre la escritura}

A comienzos de la década del 80, Pinochet afirmó que en el Chile de la Dictadura no se movía una hoja sin que él lo advirtiera (Eltit, "Tensiones"). Este diseño totalitario del poder, horizonte de cuerpos paralizados, invade la escena social a través de una política que reprime de manera brutal cualquier gesto crítico. Esto genera una escisión por cuanto los lenguajes políticos se retiran del espacio público y la censura se constituye en el signo cultural dominante. Como señala Eltit en una entrevista:

[...] Tanto la oralidad como la escritura se volvieron terrenos resbaladizos que fueron intervenidos por autocensura, que es la peor forma de censura. Entonces los lenguajes se volvieron "peligrosos", porque podían "delatar". Allí pude dimensionar el lenguaje como algo estratégico y crucial. Lo importante empezó a radicar más que en "lo dicho", en lo "no dicho", o bien en las zonas fluctuantes y ambiguas que permitían la censura y al autocensura. (Eltit, "Un territorio de zozobra" 302)

En el marco de estas tensiones, emerge la escritura de Eltit como una práctica estética y política que socava las limitaciones de los lenguajes oficiales y trabaja desde los intersticios de la palabra. Esto se traduce en una poética del arte refractario $^{12}$ que renuncia a la confortabilidad de los signos para focalizar en lo fragmentario y en el descentramiento de los saberes: “[...] sigo pensando lo literario más bien como una disyuntiva que como una zona de respuestas que dejen felices y contentos a los lectores" (Eltit, "Errante” 174). Esta idea se complementa con la

\footnotetext{
${ }^{12}$ Nelly Richard, releyendo a Benjamin, analiza la conformación de un arte refractario dentro de un conjunto de producciones chilenas posteriores al Golpe de Estado (la llamada "Escena de avanzada"). De acuerdo con la autora, estas piezas artísticas y literarias toman distancia respecto de la impostura del lenguaje oficial y de la estética marxista ortodoxa y se proponen " [...] escenificar la descomposición de las perspectivas generales, de las visiones centradas, de los cuadros enteros: una narrativa que sólo deja oír restos de lenguajes, retazos de signos, juntando hilos corridos y palabras a maltraer" (Insubordinación 27).
} 
formulación de una literatura "okupa" como imagen que define un trabajo un deseo, un proyecto de creación "[...] que se aloje y desaloje en lo abandonado, en lo transitorio, y que sobreviva apelando a un flujo de baja intensidad en perpetuo movimiento" (“En la zona” 380).

Como se observa en lo anterior, el término "política" es un significante que se asocia con frecuencia a la escritura en los textos de Eltit. Ahora bien, conviene preguntarse a qué se refiere la autora cuando habla de una “[...] opción política con el lenguaje y con la escritura de ese lenguaje” (Eltit, “Acerca del hacer" 177). Desde su perspectiva, para comprender las filiaciones políticas de un texto se hace necesario reconocer que el lenguaje no es un instrumento inocente sino que está cargado de jerarquías, historias y poderes y que lo literario contiene y exhibe los síntomas de lo social (177). Así, es posible caracterizar la dimensión social de la palabra como un placer artesanal que es " [...] ajena y propia, ya heredada y siempre ambigua, multiforme y petrificada a la vez [...]" (178). En este sentido, esta propuesta se acerca a las reflexiones de Mijaíl Bajtín en las que el lenguaje se concibe, en tanto sistema significante y escenario de las subjetividades, como un producto ideológico resultado de múltiples prácticas y tensiones que hacen a las condiciones históricas de producción. Al respecto, en el ensayo "Con la cultura en la mano" formula estas tensiones en los términos de una disputa de sentidos que desafía las leyes de la letra burocrática, reino del discurso autoritario:

La escritura literaria llegó hasta el escenario social para dislocar la hegemonía de la letra burocrática. Esa letra-ley que regía la totalidad del contrato social, letra de compra y venta, letra fundante del nacimiento y certificadora de la muerte, letra rígida. Pero la literatura, con su carga poética, estableció el espacio para densificar los sentidos, para -es un decir- romper el pragmatismo robótico de una letra-ley que ordenaba el transcurso vital en torno al poder y a la sumisión al poder. (13) 
Así las cosas, la escritura deviene en una forma de práctica política por cuanto batalla contra la estandarización del conocimiento y las experiencias; renuncia a la confortabilidad de la lengua y de las lógicas discursivas hegemónicas para adentrarse en la zona de lo discontinuo, de lo difuso y de los saberes marginados; examina los signos a contraluz con el rigor de un cirujano y los remueve con la intención de generar diálogos y espacios comunitarios alternativos. El lector que perfilan estos textos asume la incertidumbre y la problematización como las principales formas de experimentación con el conocimiento (Eltit, "Errante" 174).

\section{Conclusiones}

En este trabajo me he propuesto ingresar a los ensayos de Diamela Eltit a partir de una pregunta, de carácter general, acerca de los modos en que se articulan la crítica feminista y la reflexión sobre la escritura. Una de las ideas que organiza el análisis sostiene que estos ensayos permiten un acercamiento dinámico al pensamiento de la escritora por cuanto, en ellos, no solo se interroga acerca del carácter histórico e ideológico de los modos de significar y su incidencia en la producción de subjetividades sino que también se aboca a la construcción de genealogías literarias y culturales que manifiestan un posicionamiento estético y político disidente respecto de formaciones culturales hegemónicas. Para explicarlo en términos de Benjamin, estos ensayos se desplazan por el amplio campo de los discursos sociales para recordarnos que todo documento de cultura es, al fin de cuentas, resultado de olvidos, supresiones y derrotas (69). Atendiendo a lo señalado, he organizado una lectura del corpus de textos a partir de tres operaciones ideológico- discursivas: la deconstrucción del cuerpo, la reconstrucción de genealogías literarias femeninas y la reflexión sobre la escritura.

En lo que se refiere a la primera operación, ha sido necesario distinguir tres ejes de análisis: la construcción histórica de los cuerpos en un sentido general, la 
singularidad de los cuerpos femeninos y las problemáticas de género. Así las cosas, con una marcada influencia de la biopolítica, la autora concibe al cuerpo como un mapa sobre el que se trazan múltiples (y contradictorios) discursos sociales. La corporalidad y sus modulaciones estéticas constituyen un dispositivo a través del cual se puede leer los síntomas de una época. En ese sentido, el cuerpo de las mujeres, en el marco de la alianza y complicidad histórica entre capitalismo y patriarcado, se manifiesta como un territorio ultra vigilado en el que se disputa el contrato social. En tercer lugar, Eltit asume una conceptualización crítica y estratégica de género que toma distancia de cualquier esencialismo para señalar una gestualidad disruptiva respecto del régimen estético y político de la heterosexualidad en la que proliferan sensibilidades y afecciones múltiples.

Por otra parte, al analizar la reconstrucción de genealogías literarias femeninas he atendido a dos campos de discusión: ¿Cómo pensar las relaciones entre literatura y género? ¿Qué lugares ocupan escritoras como Gabriela Mistral y Marta Brunet en los recorridos del canon literario chileno? Como he señalado en los apartados anteriores, en estos ensayos se observa un malestar respecto de la hegemonía masculina del campo cultural y la imposición de etiquetas comerciales que evidencian una biologización de la escritura en la que se desdibuja el trabajo crítico con el lenguaje. Desde este posicionamiento crítico, Eltit explora las trayectorias vitales e intelectuales de Mistral y Brunet como una estrategia para desnudar los representaciones de género que han operado en las construcción historiográfica de ambas. Como en una especie de juego borgeano, la invocación a las voces de las antecesoras configura una poética en la que la idea de lo femenino se manifiesta como una fuerza crítica que politiza y subvierte los lenguajes y sus modos de significación.

La tercera operación que he abordado en mi análisis se refiere a las reflexiones acerca de la propia escritura a la manera de una meta-poética. Destaco, en primer lugar, que en Eltit la pregunta por la pulsión de la escritura se inscribe en un doble registro: en el ámbito del goce personal y en el de la experiencia colectiva de la violencia. En efecto, la autora expresa su vocación por la escritura como una 
forma de trabajo artesanal con la palabra y, a la vez, reconoce que sus primeros textos han estado marcados por los mecanismos de la censura y de la auto-censura. Esto ha dado lugar a la configuración de una poética "okupa" entendida como espacio de conflicto con las leyes de la gramática, como ensamblaje crítico que se aloja y desaloja en lo fragmentario y discontinuo y como estrategia política que socava y descentra permanentemente la lógica de los lenguajes institucionalizados y canonizados.

Por último, es importante destacar que en los textos analizados gravita una conceptualización de lenguaje como una práctica cultural que se inscribe sobre la materialidad de los medios comunitarios y, muy especialmente, sobre los cuerpos. Examinar las formas del lenguaje, desde esta perspectiva, implica interrogarse acerca de los procesos de conformación subjetiva en un espacio social atravesado por las lógicas capitalistas y patriarcales. La gesta de la escritura, además, se presenta como un acto de pasión y de insurrección personal (Eltit, "Errante" 171) que permite "[...] desencantarnos de este paisaje de mundo y desacomodar lo que está solidificado, silenciado e invisibilizado" (flores 221).

\section{Bibliografía}

Bajtín, Mijail. Estética de la creación verbal. México: Siglo XXI, 1995.

Barrientos, Mónica. "Sujeto y bioespacio en la narrativa de Diamela Eltit". Ciudades (in)ciertas. La ciudad y los imaginarios locales en las literaturas latinoamericanas. Adolfo de Nordenflych y Darcie Doll (compiladores). Valparaíso: Ediciones Puerto de Escape, 2009. s/p.

Benjamin, Walter. Conceptos de filosofia de la historia. La Plata: Terramar, 2007. Borges, Jorge Luis. “Kafka y sus precursores”. Otras inquisiciones. Ciudad Autónoma de Buenos Aires: Emecé, 2005. 131- 134. 
Cabrera, Mario Federico David. "Réplicas. Escritos sobre literatura, arte y política". Mitologías hoy. Revista de pensamiento, crítica y estudios literarios latinoamericanos 15 (2017): 443- 446. Web. 29 abril 2019.

Ciriza, Alejandra. "Genealogías feministas: sobre mujeres, revoluciones e Ilustración. Una mirada desde el sur”. Revista Estudos feministas 20 (2012): 613- 633. Web. 29 abril 2019.

Colaizzi, Giulia. Feminismo y teoría del discurso. Madrid: Cátedra, 1990.

Eltit, Diamela. Emergencias. Escritos sobre literatura, arte y política. Santiago de Chile: Editorial Planeta, 2000.

. "Acerca del hacer literario". Emergencias. Escritos sobre literatura, arte y política. Santiago de Chile: Editorial Planeta, 2000. 177-185. . "Errante, errática". Emergencias. Escritos sobre literatura, arte y política. Santiago de Chile: Editorial Planeta, 2000. 170- 176. . "Personaje en correspondencia". Emergencias. Escritos sobre literatura, arte y política. Santiago de Chile: Editorial Planeta, 2000. 129- 132. . "Sociedad Anónima”. Emergencias. Escritos sobre literatura, arte y política. Santiago de Chile: Editorial Planeta, 2000. 28-40. . Signos vitales. Escritos sobre literatura, arte y política. Santiago de Chile: Ediciones Universidad Diego Portales, 2008. . "Cargas y descargas". Signos vitales. Escritos sobre literatura, arte y política. Santiago de Chile: Ediciones Universidad Diego Portales, 2008. 31-40.

. "Clases de cuerpo y cuerpos de clase". Signos vitales. Escritos sobre literatura, arte y política. Santiago de Chile: Ediciones Universidad Diego Portales, 2008. 15-30. . "Contante y sonante". Signos vitales. Escritos sobre literatura, arte y política. Santiago de Chile: Ediciones Universidad Diego Portales, 2008. 271-277. 
CATEDRAL Tomada: Revista literaria latinoamericana / Journal of Latin American Literary Criticism Mario Federico David Cabrera

. "El tejido ilegal". Signos vitales. Escritos sobre literatura, arte y política. Santiago de Chile: Ediciones Universidad Diego Portales, 2008. $41-50$.

. "La plenitud de la apariencia". Signos vitales. Escritos sobre literatura, arte y política. Santiago de Chile: Ediciones Universidad Diego Portales, 2008. 148-153.

. “QQué eres?”. Signos vitales. Escritos sobre literatura, arte y política. Santiago de Chile: Ediciones Universidad Diego Portales, 2008. 257265.

. "Se deben a sus circunstancias. Baños colectivos de mujeres asiladas en el Hospital Psiquiátrico Philippe Pinel”. Signos vitales. Escritos sobre literatura, arte y política. Santiago de Chile: Ediciones Universidad Diego Portales, 2008. 215- 221.

. "Tensiones e intenciones". Signos vitales. Escritos sobre literatura, arte y política. Santiago de Chile: Ediciones Universidad Diego Portales, 2008. 180-183.

. "Un territorio de zozobra". Signos vitales. Escritos sobre literatura, arte y política. Santiago de Chile: Ediciones Universidad Diego Portales, 2008. 300-310.

. Réplicas. Escritos sobre literatura, arte y política. Santiago de Chile: Seix Barral, 2016.

. "Con este cuerpo, con este talle, no tengo envidia ni ruego a nadie". Réplicas. Escritos sobre literatura, arte y política. Santiago de Chile: Seix Barral, 2016. 28-31.

. "Con la cultura en la mano". Réplicas. Escritos sobre literatura, arte y política. Santiago de Chile: Seix Barral, 2016. 13-18. . "Dios veló sobre mí, no mis compatriotas". Réplicas. Escritos sobre literatura, arte y política. Santiago de Chile: Seix Barral, 2016. 89-92. . "En la zona intensa del otro yo misma". Réplicas. Escritos sobre literatura, arte y política. Santiago de Chile: Seix Barral, 2016. 377-392. 
. "Escuchar el dolor, oír el goce". Réplicas. Escritos sobre literatura, arte y política. Santiago de Chile: Seix Barral, 2016. 56-61.

. "La mujer o el cuerpo del delito". Réplicas. Escritos sobre literatura, arte y politica. Santiago de Chile: Seix Barral, 2016. 46-49. . "Marta Brunet en la fértil provincia". Réplicas. Escritos sobre literatura, arte y política. Santiago de Chile: Seix Barral, 2016. 99-104. . "Presentaciones, representaciones y re-presentaciones". Réplicas. Escritos sobre literatura, arte y politica. Santiago de Chile: Seix Barral, 2016. 62-73.

. "Yo soy, envejeciendo, una asiática". Réplicas. Escritos sobre literatura, arte y politica. Santiago de Chile: Seix Barral, 2016. 86-88.

Derrida, Jacques. La deconstrucción en las fronteras de la filosofía. Madrid: Cátedra, 1989.

Federici, Silvia. Calibán y la brujea. Mujeres, cuerpo y acumulación originaria. Ciudad Autónoma de Buenos Aires: Traficantes de sueños, 2010.

flores, valeria. "Escribir contra sí misma: una micro- tecnología de subjetivación política". Aproximaciones críticas a las prácticas teórico-políticas del feminismo latinoamericano. Yuderkys Espinosa Miñoso (ed). Ciudad Autónoma de Buenos Aires: En la frontera, 2010. 211- 231.

Giorgi, Gabriel. “Cuerpo”. Diccionario de Estudios Culturales Latinoamericanos. Mónica Szurmuk y Robert McKee Irwin (ed). Ciudad Autónoma de Buenos Aires/ Ciudad de México: Siglo XXI/ Instituto Mora, 2009. 6771.

Grasselli, Fabiana y Sabrina Yañez. "Los vínculos entre lenguajes/experiencias/genealogías en escritos de dos autoras feministas del sur”. Cuestiones de género: de la igualdad y la diferencia 13 (2018): 265- 280. Web. 29 abril 2019.

Grüner, Eduardo. Un género culpable. Ciudad Autónoma de Buenos Aires: Egodot, 2013. 
Miranda Medina, Camila y otras. "El feminismo como posibilidad de ampliación democrática". Autonomía feminista: aportes para la construcción del movimiento. Santiago: Izquierda Autónoma, 2018. 33-40. Web. 27 abril 2019.

Morales, Leónidas. "El discurso crítico de Diamela Eltit: cuerpo y política". Emergencias. Escritos sobre literatura, arte y política. Diamela Eltit. Santiago de Chile: Editorial Planeta, 2000. 9-16.

Richard, Nelly. La insubordinación de los signos (cambio político, transformaciones culturales y poéticas de la crisis). Santiago de Chile: Editorial Cuarto Propio, 1994.

. "La crítica feminista como modelo de crítica cultural". Debate feminista 40 (2009): 75- 85.

. "Cuestionario". En torno a los estudios culturales. Localidades, trayectorias y disputas. Nelly Richard, coordinadora. Santiago: Arcis/ Clacso, 2010. 67-82.

. "La generalización masculina del intelectual público". Catedral Tomada. Revista de crítica literaria latinoamericana 6 (2016): 184- 189.

Richard, Nelly. Feminismo, género y diferencia(s). Santiago de Chile: Palinodia, 2018.

Segato, Rita. La escritura en el cuerpo de las mujeres asesinadas en Ciudad Juárez. Territorios, soberanía y crímenes de segundo estado. Ciudad Autónoma de Buenos Aires: Tinta Limón, 2013 